Canadian

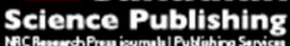

Applied Physiology, Nutrition, and Metabolism Physiologie appliquée, nutrition et métabolisme

\title{
Food parenting practices and their association with child nutrition risk status: comparing mothers and fathers
}

\begin{tabular}{|r|l|}
\hline Journal: & Applied Physiology, Nutrition, and Metabolism \\
\hline Manuscript ID & apnm-2016-0572.R2 \\
\hline Manuscript Type: & Article \\
\hline Date Submitted by the Author: & 26-Jan-2017 \\
\hline Complete List of Authors: & $\begin{array}{l}\text { Watterworth, Jessica; University of Guelph, Family Relations and Applied } \\
\text { Nutrition; University of Toronto, Nutritional Sciences } \\
\text { Mackay, Joy; University of Guelph, Family Relations and Applied Nutrition } \\
\text { Buchholz, Andrea; University of Guelph, } \\
\text { Darlington, Gerarda; University of Guelph, Dept of Mathematics and } \\
\text { Statistics } \\
\text { Randall Simpson, Janis; University of Guelph } \\
\text { Ma, David; University of Guelph, } \\
\text { Haines, Jess; University of Guelph, Family Relations and Applied Nutrition }\end{array}$ \\
\hline Keyword: & child, parent, nutrition status, father, food parenting practices \\
\hline \multicolumn{2}{|c}{} \\
\hline
\end{tabular}

SCHOLARONE $^{\text {IM }}$

Manuscripts 
Food parenting practices and their association with child nutrition risk status: comparing mothers and fathers

Jessica C. Watterworth, ${ }^{1}$ Joy M. Mackay, ${ }^{1}$ Andrea C. Buchholz, ${ }^{1}$ Gerarda Darlington, ${ }^{2}$ Janis A. Randall Simpson, ${ }^{1}$ David W.L. Ma, ${ }^{3}$ Jess Haines, ${ }^{1}$ on behalf of the Guelph Family Health Study

${ }^{1}$ Dept Family Relations and Applied Nutrition, University of Guelph ${ }^{2}$ Dept of Mathematics and Statistics, University of Guelph

${ }^{3}$ Dept Human Health and Nutritional Sciences, University of Guelph

Corresponding Author: Dr. Jess Haines, jhaines@uoguelph.ca, 519-824-4120 x53780

Jessica C. Watterworth, jwatterw@mail.uoguelph.ca

Joy M. Mackay, mackayj@mail.uoguelph.ca

Andrea C. Buchholz, abuchhol@uoguelph.ca

Gerarda Darlington, gdarling@uoguelph.ca

Janis A. Randall Simpson, rjanis@uoguelph.ca

David W.L.Ma, davidma@uoguelph.ca 


\section{ABSTRACT}

In Canada, little is known about how food parenting practices are associated with young children's dietary intakes and no studies have examined food parenting practices of Canadian fathers. This study aimed to examine associations between food parenting practices and preschool-age children's nutrition risk. We conducted a cross-sectional analysis of 31 two-parent families; 31 mothers, 31 fathers and 40 preschool-age children. Parents completed an adapted version of the Comprehensive Feeding Practices Questionnaire. We calculated children’s nutrition risk using their NutriSTEP ${ }^{\circledR}$ score. To account for sibling association, we used generalized estimating equations, adjusting for child age, sex, household income, and parental BMI. Both mothers' and fathers' involvement of children in meal preparation were associated with lower child nutrition risk (mother $\widehat{\beta}=-3.45, \mathrm{p}=0.02$; father $\widehat{\beta}=-1.74, \mathrm{p}=0.01$ ), as were their healthy home environment scores (mother $\widehat{\beta}=-8.36, \mathrm{p}<0.001$; father $\widehat{\beta}=-2.69, \mathrm{p}=0.04)$. Mothers' encouragement of balance and variety was associated with lower nutrition risk $(\widehat{\beta}=-8.88$, $\mathrm{p}=0.01$ ), whereas mothers' use of food as a reward was associated with higher nutrition risk $(\widehat{\beta}=4.67, p<0.001)$. Fathers' modeling of healthy behaviours was associated with lower nutrition risk $(\hat{\beta}=-2.21, p=0.01)$, whereas fathers' restriction for health $(\hat{\beta}=2.21, p=0.03)$ and pressure-toeat scores $(\widehat{\beta}=3.26, p=<0.001)$ were associated with higher nutrition risk. No associations were found between child nutrition status and parental emotion regulation, control, monitoring, nor restriction for weight. In conclusion, both mothers' and fathers' food parenting practices are associated with their children's nutrition status. Fathers should be included in food parenting practices interventions.

Keywords: Child; parent; food parenting practices; nutrition status; father 


\section{INTRODUCTION}

Providing optimal nutrition is vital during the growth and development of toddlers and preschool-age children. Poor dietary intake and an unhealthy eating environment can lead to nutrition risk as well as long-term health problems, such as diabetes, cancer, and heart disease (Eyre et al. 2004; Rylatt \& Cartwright 2016). In Canada, it is estimated that between 11-30\% of toddler and preschool-age children are at moderate nutrition risk and 10-17\% are at high nutrition risk (Randall Simpson et al. 2008; Watson-Jarvis et al. 2011). Researchers have explored the associations between child health status and obesity risk with particular parenting practices, specifically identifying feeding-specific styles, now referred to as "food parenting practices" (Vaughn et al. 2016). There is growing evidence that food parenting practices have a strong influence on young children's dietary intake, and therefore their nutrition risk (Blissett et al. 2006; Savage et al. 2007).

Although mothers often hold the primary role in feeding children, recent findings show fathers also play a role in food-related practices (Khandpur et al. 2014). Fathers' increased responsibility in child feeding is likely due to changes in women's employment patterns, increasing numbers of single fathers, and changing social norms regarding fathers' roles (Bianchi 2000; Savage et al. 2007; Yeung et al. 2001). While substantial research has explored maternal influence on their children's eating habits and dietary intake (Durão et al. 2015; Matheson et al. 2006; RifasShiman et al. 2011; Rodgers et al. 2014; Webber et al. 2010), fathers are often underrepresented or excluded entirely (Davison et al. 2016; Phares et al. 2005). This is problematic considering the increasing number of fathers who co-parent alongside their spouses, specifically in food parenting practices. A recent study by Khandpur and colleagues found that $62 \%$ of the fathers in the study reported sharing the responsibilities related to food parenting with their child's mother, 
and approximately $15 \%$ of the fathers reported full responsibility for food parenting (Khandpur et al. 2016). Although paternal data are limited, recent studies have found associations between fathers' food parenting practices and child dietary patterns and eating behaviour. A crosssectional study of 150 fathers in the US found positive associations between fathers' use of restriction and pressure to eat, and child food avoidance, food fussiness, emotional under eating, and emotional over eating (Vollmer et al. 2015). These results underscore the important role fathers' food parenting practices may play in the development of children's dietary intake patterns. To date, only one Canadian study has explored food parenting practices among parents of young children; Shea and colleagues found that weight status was lower in children whose parents pressured them to eat (Shea et al. 2010). However, this study did not examine associations between food parenting practices and child dietary patterns or eating behaviour. In addition, this study combined information on food parenting practices across parents without distinguishing fathers from mothers; thus, no Canadian studies have explored the association between fathers' food parenting practices and child nutrition status, as distinct from mothers'. Given that feeding and parenting norms in Canada may differ from those in the US, it is important to examine these associations within a Canadian context. Using data from mothers and fathers recruited in a family-based study in Ontario Canada, the objective of this study was to determine the associations between mothers' and fathers' food parenting practices and their children's nutrition risk. 


\section{METHODS}

\section{Recruitment and Eligibility}

Baseline data were obtained from the Guelph Family Health Study (GFHS) pilot, a family-based cohort study in southern Ontario, Canada. A total of 44 families were recruited for the pilot phase of the GFHS through flyers, social media, a local family health team, the Guelph Community Health Centre, and word-of-mouth in Wellington County, Ontario, Canada. Families were eligible to participate in the study if they had at least one child aged 1.5-5 years at the time of recruitment, if they lived in the Guelph area (i.e., Wellington County - includes Guelph, Rockwood, Fergus, Elora, Mount Forest, Puslinch), and if they did not plan to relocate within the first year of the study. While the inclusion criteria for the study allow participation of same-sex couple headed families, thus far, all 2 parent families who have participated are headed by a man and a woman. Since we wanted to compare mothers and fathers, we only included two-parent families consisting of mother-father dyads in this study $(n=31$; Table 1$)$. All study procedures were administered after the parents of the participants gave written, informed consent. The study was approved by the University of Guelph Research Ethics Board.

\section{Measures}

\section{Food parenting practices}

To assess food parenting practices, both mothers and fathers completed 31 out of 49 items of the Comprehensive Feeding Practices Questionnaire (CFPQ) (Musher-Eizenman \& Holub 2007). To account for participant burden due to length of the questionnaire, questions contributing to the same food parenting practice with similar wording were excluded (e.g., "Do you let your child eat whatever s/he wants?" was included, whereas "Do you allow this child to eat snacks whenever s/he wants" was not). The section 'teaching for nutrition' was also excluded since 
overlapping questions addressed this topic. We assessed the following 11 food parenting practices: allowing child to control his/her food intake (3 items), using food to regulate child emotions ( 2 items), encouragement of balance and variety (2 items), providing a healthy home environment (3 items), using food as a reward ( 3 items), involving children in meal preparation (2 items), modeling healthy eating behaviours ( 2 items), monitoring unhealthy foods (4 items), pressure to eat (3 items), restriction for health ( 2 items), restriction for weight control (5 items). To measure the reliability for the adapted version, we ran Cronbach's alpha scores for each food parenting practice and compared them to the scores associated with the entire validated CFPQ (Table 2). As the Cronbach's alpha scores generated for the adapted versus the full version were comparable, we concluded that they were fair representations of each food parenting practice. For each question, the CFPQ provided one of two 5-point Likert response scales: one ranging from "disagree," to "agree", and the other ranging from "never" to "often." These responses were coded into a numerical score from one to five and then averaged to create a score for each food parenting practice. The scores indicate how strongly the individual believes that he/she participates in each of these feeding practices. The CFPQ was completed separately by both parents for each of their children, resulting in both maternal and paternal scores for each individual child. Parents with multiple children may have contributed more than one observation towards the overall mean feeding practice scores, as seen in Table 2.

\section{Child nutrition status}

The primary parent (the original parent to enroll in the study) completed the NutriSTEP ${ }^{\circledR}$ questionnaire for each of their children. Developed by Registered Dietitians, NutriSTEP ${ }^{\circledR}$ has been tested and deemed a valid and reliable tool to assess nutrition risk in preschoolers by screening for eating habits and identifying nutrition issues (Randall Simpson et al. 2008). This 
17-item questionnaire consists of five subscales: eating behaviours, dietary intake, parental concerns about food and activity, screen time duration, and the use of supplements (Randall Simpson et al. 2008). During the development of NutriSTEP ${ }^{\circledR}$, three phases were conducted to test face and content validity (phase I and II) and criterion validity and retest reliability (phase III) in order to evaluate the nutrition risk status of a sample of multicultural Canadian preschoolers (Randall Simpson et al. 2008). Results from the questionnaire were tested against medical history, three days of diet recall, and anthropometric measures (Randall Simpson et al. 2008). Each individual question provided a tailored Likert scale, which was then coded into a numerical score through the use of the designated NutriSTEP ${ }^{\circledR}$ coding system. These scores were then summed to generate a nutrition risk score for each child (ranging from 0 to 68), with higher score representing greater nutrition risk.

Statistical analysis

All analyses were performed using Statistical Package for the Social Sciences (SPSS for Mac version 23, IBM, Chicago, IL). To account for correlations among siblings in our sample, the generalized estimating equations (GEE) approach was used when investigating linear associations between an independent variable: food parenting practices (i.e., control, emotion regulation, encourage balance and variety, environment, food as reward, involvement, modeling, monitoring, pressure, restriction for health, and restriction for weight control) and the dependent variable: child nutrition status (NutriSTEP ${ }^{\circledR}$ score). The covariates entered in this model were household income, child age, child gender and parental Body Mass Index (BMI). Child age was calculated using the child's birthdate and the date of his/her baseline assessment. The primary parent provided gender for both parents and children during study enrolment. The primary parent provided information on annual household income by selecting an income bracket on the 
baseline questionnaire. Both parents had their height measured using a stadiometer. The averages of two height measures were performed if the values were within $0.5 \mathrm{~cm}$, if not, a third measure was taken and the two closest measures were averaged. Parental weight measures were performed using the BOD POD ${ }^{\mathrm{TM}}$ digital scale. BMI was calculated as weight in kilograms $(\mathrm{kg})$ divided by height in metres squared $\left(\mathrm{m}^{2}\right)$. Significance was determined as $p<0.05$. 


\section{RESULTS}

\section{Sample}

One mother was unsuccessful at completing the CFPQ for control and emotion regulation; five mothers and six fathers were unsuccessful at completing the CFPQ for encouraging balance and variety, providing a healthy environment, using food as a reward, involvement, and modeling; and two mothers did not complete the CFPQ for restriction for health and weight; these were excluded from the analyses for those specific feeding practices. Thus, the final sample consisted of 31 two-parent families (31 mothers, 31 fathers, and 40 children). Participant demographic information is presented in Table 1. Children's mean age was 3.5 years and approximately 52\% of the children were male. Mean age of parents was 35 years, $50 \%$ of the parents were male, and $39 \%$ of the families made a household income of over 100,000 dollars (CDN) annually. The mean BMI of the parents and BMI z-score of the children in the sample were $28 \mathrm{~kg} / \mathrm{m}^{2}$ and 0.52 respectively. Seven percent of the children were at moderate nutrition risk and twelve percent were at high nutrition risk. A baseline comparison of the mean scores of mother and father feeding practice scores are presented in Table 2.

\section{Associations between maternal and paternal food parenting practices and nutrition risk} Mother food parenting practices

Mothers' encouragement of balance and variety $(\widehat{\beta}=-9.88,95 \% \mathrm{CI}-15.32,-2.43, \mathrm{p}=0.01)$, provision of a healthy home environment $(\widehat{\beta}=-8.36,95 \% \mathrm{CI}-11.66,-5.07, \mathrm{p}<0.001)$, and involvement of child in food preparation $(\widehat{\beta}=-3.45,95 \% \mathrm{CI}-6.35,-0.55, \mathrm{p}=0.02$; Table 3$)$ were associated with lower child nutrition risk. Mothers' use of food as a reward $(\widehat{\beta}=4.67,95 \% \mathrm{CI}$ 2.27, 6.78, $\mathrm{p}<0.001$; Table 3) were associated with higher child nutrition risk. Mothers' use of food to regulate their child's emotions, allowing their child to control their food intake, modeling 
healthy eating behaviours, monitoring unhealthy food intake, pressuring their child to eat, restriction for health and restriction for weight were not found to be significantly associated with child nutrition risk (Table 3).

Father food parenting practices

Fathers' involvement of children during meal preparation $(\widehat{\beta}=-1.74,95 \% \mathrm{CI}-2.96,-0.52, \mathrm{p}=$ $0.01)$, modeling healthy eating behaviours $(\widehat{\beta}=-2.21,95 \% \mathrm{CI}-3.93,-0.49, \mathrm{p}=0.01)$ and providing a healthy home environment $(\widehat{\beta}=-2.69,95 \% \mathrm{CI}-5.28,-0.10, \mathrm{p}=0.04$; Table 3$)$ were associated with lower child nutrition risk. Conversely, fathers' practices of pressured feeding $(\widehat{\beta}$ $=3.26,95 \%$ CI $1.53,4.98, p<0.001)$ and restriction for health $(\widehat{\beta}=2.21,95 \%$ CI $0.18,4.23, p=$ 0.03; Table 3) were found to be associated with higher child nutrition risk. Fathers' use of food to regulate their child's emotions, allowing their child to control their food intake, encouragement of balance and variety, using food as a reward, monitoring unhealthy food intake, and restricting for weight were not significantly associated with child nutrition risk (Table 3). 


\section{DISCUSSION}

In this sample of Canadian parents of preschool-age children, both mothers' and fathers' involvement of children in meal preparation and the provision of a healthy home environment were associated with lower child nutrition risk. Mothers' encouragement of balance and variety was associated with lower nutrition risk, whereas mothers' use of food as a reward was associated with higher nutrition risk. Fathers' modeling of healthy eating was associated with lower nutrition risk, whereas father restriction for health and pressure to eat scores were associated with higher nutrition risk. Neither mothers' nor fathers' control, emotion regulation, monitoring, nor restriction for weight were significantly associated with child nutrition risk. In our study, we found that fathers', but not mothers', modeling of healthful eating behaviour was associated with a lower children's nutrition risk. This finding demonstrates that fathers may have a potentially protective influence on their young children's nutrition status and that children may be more strongly influenced by the eating behaviours of their father than their mother. A recent home intervention study by Holley and colleagues found that children increased their consumption of disliked vegetables when parents modeled eating the particular vegetable with enthusiasm (Holley et al. 2015). Our findings that fathers' modeling is more strongly associated with lowering their children's nutrition risk status than is mother modeling, may be due to the fact that fathers are more expressive and enthusiastic when demonstrating modeling practices; however, more research is needed to determine the mechanism by which father modeling influences children's dietary intake. This is important given that many family-based healthy eating initiatives focus mainly on mothers as the target for intervention since they are considered the "gatekeeper" of the household (Adamo \& Brett 2014). By excluding fathers, family-based interventions may neglect to utilize fathers' potential protective influence on their children's 
nutrition status. Our results suggest that fathers should be included in child feeding research and intervention strategies.

Additionally, our results support previous findings that indicate the creation of a healthful home environment is important to support healthful eating behaviours in children (Melbye et al. 2013). Our study found that mothers who report promoting a well-balanced food intake (including the consumption of varied and healthy food choices), make healthy foods available at home, and encourage their child's involvement in meal planning and preparation, were associated with children with lower nutrition risk. Similarly, fathers who encourage their child's involvement in meal planning and preparation had children with lower nutrition risk. Taken together, these results suggest that child-feeding initiatives should support parents in making healthy home environments, as well as provide strategies in involving children in grocery shopping, meal preparation, and cooking.

Fathers', but not mothers', use of coercive food parenting practices of pressuring their children to eat was found to be associated with higher nutrition risk score among children. These findings support existing research, which has shown that coercive food parenting practices may have a negative influence on child dietary intake, however this was not specific to fathers (Vaughn et al. 2016). Melbye and colleagues found that children subject to restriction for health purposes were inversely associated with child vegetable intake (Melbye et al. 2013). Similarly, Durão and colleagues found that parental use of restriction, monitoring, and control was associated with 11$18 \%$ lower odds of adequate fruit and vegetable consumption among children (Durão et al. 2015). Pressuring or restricting the intake of certain foods may influence children's perception, and thus, their intake, of those foods. For example, children whose parents pressure them to eat vegetables, perceive vegetables as less desirable than children whose parents do not (Galloway et 
al. 2005). It is also possible that children's eating behaviours may influence parents' food practices (Haycraft \& Blissett 2008). For example, the use of coercive feeding practices may be in response to a child's picky eating patterns; parents may use these food parenting practices in an attempt to improve their child's eating habits and nutrition status. Prospective research is needed to elucidate the temporal order of the association between food parenting practices and dietary intake among Canadian families. In addition, we found that mothers' use of the food parenting practice which uses food as a reward was also associated with higher child nutrition risk, whereas fathers were not seen to have the same effect. Similarly, fathers' practice of restricting food for health purposes was found to be associated with high child nutrition risk. This may be due to the fact that mothers and fathers implement food as a reward and restriction differently. Since the development of defining food parenting practices does not differentiate between mothers and fathers (Vaughn et al. 2016), more research is needed to explore how mothers and fathers compare when implementing each practice.

Our study had a number of key strengths. First, the strong representation of fathers within the sample is unique within food parenting practices studies. This allowed for a more inclusive analysis of the family feeding environment and allowed examination of associations between both maternal and paternal feeding and child nutrition risk. Secondly, food parenting practices were evaluated separately for each child, versus parents' general household food parenting practices. This approach takes into account the possibility that parents' food parenting practices differ as a result of each of their individual children's feeding behaviours. By looking at the food parenting practices exhibited to each individual child within the household, we may be able to better understand the association between food parenting practices and nutrition risk than could be obtained using a general assessment of a parent's household food parenting practices across 
all of their children. However, some limitations should be considered when interpreting study results. First, our sample was relatively small, which could have resulted in increased risk for type 2 error in our non-significant findings. Secondly, the participants in the sample were of relatively high socio-economic status and the majority of parents identified as 'white'. Thus, the results may not be generalizable to more socioeconomically and ethnically diverse populations. All measures were collected by self-report and thus may be subject to social desirability bias. This reporting bias would most likely bias estimates towards the null. Additionally, the NutriSTEP ${ }^{\circledR}$ questionnaire was completed by only one parent and thus may not accurately represent the other parents' viewpoint related to child's nutrition status.

Overall, it was found that mothers' and fathers' involvement of children in meal preparation and the provision of a healthy home environment were associated with lower child nutrition risk, whereas coercive food parenting practices were associated with higher child nutrition risk. Father modeling was also associated with lower child nutrition risk. These findings suggest that both mothers' and fathers' food parenting practices may be associated with children's nutrition status. These results also underscore the importance of including fathers in research and interventions focused on child feeding. Future research should include a larger, more diverse sample of families to increase power and to allow for more generalizable findings.

\section{Conflict of interest statement}

No honorarium, grant, or other form of payment was given to the authors to produce this manuscript. The authors report no conflicts of interest.

\section{Acknowledgements}

We would like to sincerely thank all of the participating families for their time and involvement in the Guelph Family Health Study. We are indebted to Owen Krystia for technical assistance. 
We are also grateful for the study coordinator, Angela Annis, and the many research assistants for collecting and organizing these data. 


\section{References}

Adamo, K. B., \& Brett, K. E. 2014. Parental Perceptions and Childhood Dietary Quality. Matern. Child Health J. 18(4), 978-995. doi:10.1007/s10995-013-1326-6.

Bianchi, S. M. 2000. Maternal employment amd time with children: Dramatic change or surprising continuity? Demography, 37(4), 401-414.

Blissett, J., Meyer, C., \& Haycraft, E. 2006. Maternal and paternal controlling feeding practices with male and female children. Appetite, 47, 212-219. doi:10.1016/j.appet.2006.04.002.

Davison, K. K., Charles, J. N., Khandpur, N., \& Nelson, T. J. 2017. Fathers’ Perceived Reasons for Their Underrepresentation in Child Health Research and Strategies to Increase Their Involvement. Matern. Child Health J. 21(2), 267-274. doi:10.1007/s10995-016-2157-z.

Durão, C., Andreozzi, V., Oliveira, A., Moreira, P., Guerra, A., Barros, H., et al. 2015. Maternal child-feeding practices and dietary inadequacy of 4-year-old children. Appetite, 92, 15-23. doi:10.1016/j.appet.2015.04.067.

Eyre, H., Kahn, R., \& Robertson, R. M. 2004. Preventing cancer, cadiovascular disease, and diabetes: a common agenda for the American Cancer Society, the American Diabetes Association, and the American Heart Association. Circulation, 109(25), 3244-3255. doi:10.1161/01.CIR.0000133321.00456.00.

Galloway, A. T., Fiorito, L., Lee, Y., \& Birch, L. L. 2005. Parental pressure, dietary patterns, and weight status among girls who are "picky eaters." J. Amer. Diet. Assoc. 105(4), 541-548. doi:10.1016/j.jada.2005.01.029.

Haycraft, E. L., \& Blissett, J. M. 2008. Maternal and Paternal Controlling Feeding Practices: Reliability and Relationships With BMI. Obesity, 16(7), 1552-1558. 
doi:10.1038/oby.2008.238.

Holley, C. E., Haycraft, E., \& Farrow, C. 2015. "Why don”t you try it again?' A comparison of parent led, home based interventions aimed at increasing children's consumption of a disliked vegetable. Appetite, 87, 215-222. doi:10.1016/j.appet.2014.12.216.

Khandpur, N., Blaine, R. E., Fisher, J. O., \& Davison, K. K. 2014. Fathers' child feeding practices: A review of the evidence. Appetite, 78, 110-121. doi:10.1016/j.appet.2014.03.015

Khandpur, N., Charles, J., \& Davison, K. K. 2016. Fathers' Perspectives on Coparenting in the Context of Child Feeding. Appetite, 78, 110-121. doi:10.1089/chi.2016.0118.

Matheson, D. M., Robinson, T. N., Varady, A. N. N., \& Killen, J. D. 2006. Do MexicanAmerican Mothers' Food-Related Parenting Practices Influence Their Children's Weight and Dietary Intake? J. Amer. Diet. Assoc. 106(11), 1861-1865. doi:10.1016/j.jada.2006.08.004.

Melbye, E. L., Øgaard, T., \& Øverby, N. C. 2013. Associations between parental feeding practices and child vegetable consumption. Mediation by child cognitions? Appetite, 69, 23-30. doi:10.1016/j.appet.2013.05.005

Musher-Eizenman, D., \& Holub, S. 2007. Comprehensive Feeding Practices Questionnaire: Validation of a New Measure of Parental Feeding Practices. J. Pediatr. Psych. 32(8), 960972.

Phares, V., Lopez, E., Fields, S., Kamboukos, D., \& Duhig, A. M. 2005. Are fathers involved in pediatric psychology research and treatment? J. Pediatr. Psych. 30(8), 631-643. doi:10.1093/jpepsy/jsi050.

Randall Simpson, J., Keller, H., Rysdale, L., \& Beyers, J. 2008. Nutrition Screening Tool for 
Every Preschooler $\left(\right.$ NutriSTEP ${ }^{\circledR}$ ): Validation and test-retest reliability of a parentadministered questionnaire assessing nutrition risk of preschoolers. Eur. J. Clin. Nutr. 62(6), 770-780. doi:10.1038/sj.ejcn.1602780.

Rifas-Shiman, S. L., Sherry, B., Scanlon, K., Birch, L. L., Gillman, M. W., \& Taveras, E. M. 2011. Does maternal feeding restriction lead to childhood obesity in a prospective cohort study? Arch. Dis. Child. 96(3), 265-269. doi:10.1136/adc.2009.175240.

Rodgers, R. F., Paxton, S. J., Mclean, S. A., Campbell, K. J., Wertheim, E. H., Skouteris, H., et al. 2014. Maternal negative affect is associated with emotional feeding practices and emotional eating in young children. Appetite, 80, 242-247. doi:10.1016/j.appet.2014.05.022.

Rylatt, L., \& Cartwright, T. 2016. Parental feeding behaviour and motivations regarding preschool age children: A thematic synthesis of qualitative studies. Appetite, 99, 285-297. doi:10.1016/j.appet.2015.12.017.

Savage, J. S., Fisher, J. O., \& Birch, L. L. 2007. Parental Influence on Eating Behaviour: Conception to Adolescence. J. Law Med. \& Ethics, 35(1), 22-34.

Shea, C., Dwyer, J. J. M., Shaver Heeney, E., Goy, R., \& Randall Simpson, J. 2010. The effect of parental feeding behaviours and participation of children in organized sports/activities on child body mass index. Can. J. Diet. Prac. Res. 71(4), 87-93. doi:10.3148/71.4.2010.178.

Vaughn, A. E., Ward, D. S., Fisher, J. O., Faith, M. S., Hughes, S. O., Kremers, S. P. J., et al. 2016. Fundamental constructs in food parenting practices: A content map to guide future research. Nutr. Rev. 74(2), 98-117. doi:10.1093/nutrit/nuv061.

Vollmer, R. L., Adamsons, K., Foster, J. S., \& Mobley, A. R. 2015. Association of fathers’ 
feeding practices and feeding style on preschool age children's diet quality, eating behavior and body mass index. Appetite, 89, 274-281. doi:10.1016/j.appet.2015.02.021.

Watson-Jarvis, K., McNeil, D., Fenton, T. R., \& Campbell, K. 2011. Implementing the Nutrition Screening Tool For Every Preschooler (NutriSTEP ${ }^{\circledR}$ ) In Community Health Centres. Can. J. Diet. Prac. Res. 72, 96-98. doi:10.3148/72.2.2011.96.

Webber, L., Cooke, L., Hill, C., \& Wardle, J. 2010. Associations between children's appetitive traits and maternal feeding practices. J. Amer. Diet. Assoc. 110(11), 1718-1722. doi:10.1016/j.jada.2010.08.007.

Yeung, W. J., Sandberg, J. F., Davis-Kean, P. E., \& Hofferth, S. L. 2001. Children's Time With Fathers in Intact Families. J. Marriage Fam. 63, 136-154. 
Table 1: Characteristics of mothers, fathers and their preschool-age children in the Guelph Family Health Study pilot.

\begin{tabular}{lcc}
\hline Variable & Children & Parents \\
& $(\mathrm{N}=40)$ & $(\mathrm{N}=62)$ \\
\hline
\end{tabular}

Gender, \%

Male

52.5

50.0

Age (year), Mean (SD)

Household Income, \%*

$<\$ 40,000$

$\begin{array}{cc}- & 9.7 \\ - & 25.8 \\ - & 6.5 \\ - & 19.4 \\ - & 29.0 \\ - & 9.6\end{array}$

Ethnicity, \%

Caucasian

75.0

80.6

Other

25.0

19.4

Weight Status (BMI $\dagger$ ), Mean (SD)

$0.52(1.05) \quad 28.01(6.31)$

Nutrition Status (NutriSTEP ${ }^{\circledR}$ score), \%

Low risk $($ score $\leq 20)$

80.0

Moderate risk (score 21-25)

7.5

High risk (score $\geq 26$ )

12.5

$* \overline{\mathrm{N}}=31$; sample based on the primary parent's response to household questionnaire.

$\uparrow$ BMI was used for adult weight status; BMI z-score was used for child weight status to account for age and sex. 
Table 2: Mean scores of mothers' and fathers' food parenting practices and comparison of the Cronbach's alphas of the full Comprehensive Feeding Practices Questionnaire and the adapted version

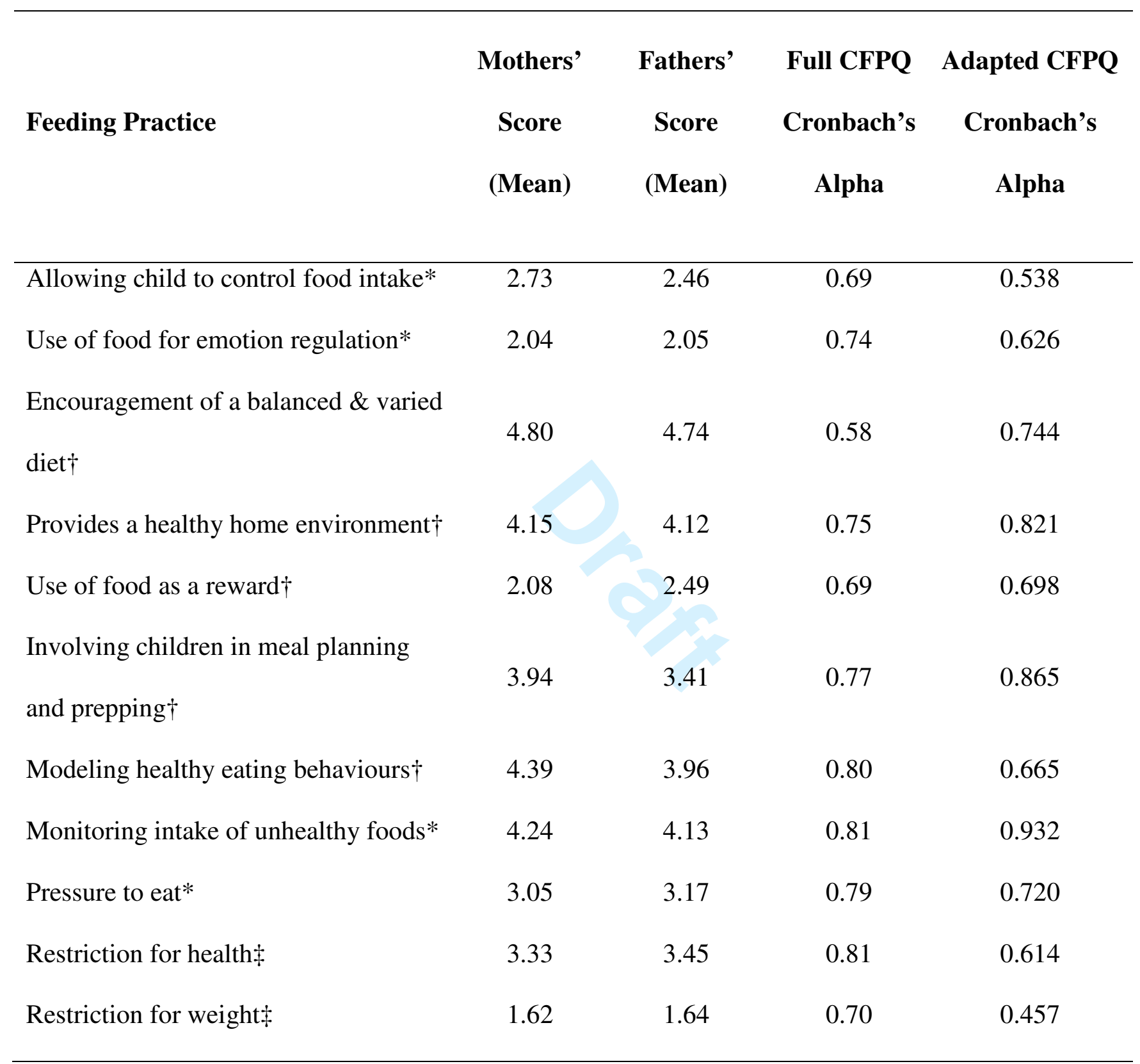

$* \mathrm{~N}_{\text {mothers }}=39 ; \mathrm{N}_{\text {fathers }}=40$
$\dagger \mathrm{N}_{\text {mothers }}=35 ; \mathrm{N}_{\text {fathers }}=34$
$\dagger \mathrm{N}_{\text {mothers }}=38 ; \mathrm{N}_{\text {fathers }}=40$ 
Table 3: Results of generalized estimating equations analyses of mother and father Comprehensive Feeding Practices Questionnaire scores with Nutrition Risk Score (NutriSTEP ${ }^{\circledR}$ score).

\begin{tabular}{|c|c|c|c|c|}
\hline \multirow{4}{*}{ Food Parenting Practice } & \multicolumn{2}{|c|}{ Mothers } & \multicolumn{2}{|c|}{ Fathers } \\
\hline & Adjusted & & Adjusted & \\
\hline & Estimate* & P-value & Estimate* & P-value \\
\hline & $(95 \% \mathrm{CI})$ & & $(95 \% \mathrm{CI})$ & \\
\hline \multirow[b]{2}{*}{ Allowing child to control food intake } & -0.91 & & -0.02 & \multirow[b]{2}{*}{0.99} \\
\hline & $(-5.80,3.97)$ & 0.71 & $(-4.88,4.84)$ & \\
\hline \multirow[b]{2}{*}{ Use of food for emotion regulation } & 1.71 & \multirow[b]{2}{*}{0.61} & -2.23 & \multirow[b]{2}{*}{0.27} \\
\hline & $(-4.78,8.20)$ & & $(-6.17,1.72)$ & \\
\hline Encouragement of a balanced \& & -8.88 & \multirow[b]{2}{*}{0.01} & -0.28 & \multirow[b]{2}{*}{0.91} \\
\hline varied diet & $(-15.32,-2.43)$ & & $(-4.98,4.43)$ & \\
\hline Provides a healthy home & -8.36 & & -2.69 & \multirow[b]{2}{*}{0.04} \\
\hline environment & $(-11.66,-5.07)$ & $<0.001$ & $(-5.28,-0.10)$ & \\
\hline \multirow[b]{2}{*}{ Use of food as a reward } & 4.67 & & 0.34 & \multirow[b]{2}{*}{0.74} \\
\hline & $(2.27,6.78)$ & $<0.001$ & $(-1.63,2.31)$ & \\
\hline Involving children in meal planning & -3.45 & \multirow[b]{2}{*}{0.02} & -1.74 & \multirow[b]{2}{*}{0.01} \\
\hline and prepping & $(-6.35,-0.55)$ & & $(-2.96,-0.52)$ & \\
\hline Modeling healthy eating behaviours & $\begin{array}{c}-1.30 \\
(-5.63,3.02)\end{array}$ & 0.55 & $\begin{array}{c}-2.21 \\
(-3.93,-0.49)\end{array}$ & 0.01 \\
\hline Monitoring intake of unhealthy & -3.10 & & -0.78 & \\
\hline foods & $(-7.99,1.80)$ & 0.22 & $(-2.55,0.99)$ & 0.39 \\
\hline
\end{tabular}




\begin{tabular}{|c|c|c|c|c|}
\hline \multirow[b]{2}{*}{ Pressure to eat } & 1.45 & \multicolumn{3}{|c|}{3.26} \\
\hline & $(-0.57,3.48)$ & 0.16 & $(1.53,4.98)$ & $<0.001$ \\
\hline Restriction for health & $\begin{array}{c}2.02 \\
(-0.32,4.35)\end{array}$ & 0.09 & $\begin{array}{c}2.21 \\
(0.18,4.23)\end{array}$ & 0.03 \\
\hline Restriction for weight & $\begin{array}{c}1.50 \\
(-5.35,8.35)\end{array}$ & 0.67 & $\begin{array}{c}0.20 \\
(-6.27,6.67)\end{array}$ & 0.95 \\
\hline
\end{tabular}

*Model was adjusted for child age and gender, household income, and parental BMI. 